\title{
SSynthesis
}

International Scientific Conference of IT and Business-Related Research

\section{JEZIK STRUKE: ZAVARIVANJE DANAS}

\section{LANGUAGE FOR SPECIFIC PURPOSES: WELDING TODAY}

\author{
Olivera Popović1, Radica Prokić-Cvetković1, Uroš Lukić1, Radomir Jovičić2, Dragan Cvetković ${ }^{3}$ \\ ${ }^{1}$ Univerzitet u Beogradu, Mašinski fakultet, Kraljice Marije 16, Beograd, Srbija \\ ${ }^{2}$ Univerzitet u Beogradu, Inovacioni centar Mašinskog fakulteta, Kraljice Marije 16, Beograd, Srbija \\ ${ }^{3}$ Univerzitet Singidunum, Kumodraška 261 a, Beograd, Srbija
}

\begin{abstract}
Apstrakt:
U inženjerstvu, kao i u drugim oblastima nauke, veoma je važno precizno i jasno definisati određene pojmove. Tako je i u zavarivanju neophodno postojanje opšteprihvaćene terminologije razumljive svima. Nedosledna terminologija pravi probleme u radu, komunikaciji i dovodi do grešaka, jer ljudi pod istim nazivom podrazumevaju različite pojmove. Posledice toga nekada mogu biti i izgubljeni ljudski životi. Nekada su ovu oblast uglavnom uređivali standardi; međutim, uvođenjem prakse usvajanja standarda bez prevođenja na srpski jezik, a prestankom važenja starih, stvaraju se novi problemi. Takođe, razvoj elektronike omogućio je revolucionaran razvoj uređaja sa mnogo novih funkcija, pa se postavlja pitanje da li nazive tih funkcija treba prevoditi ili ne, jer često ne postoji adekvatan termin, bez obzira na bogatstvo srpskog jezika.

Cilj rada je, da kroz puno primera, prikaže trenutno stanje terminologije i odgovarajućih standarda u zavarivanju, i da ukaže na neophodnost uvođenja profesionalizma u radu i prevođenju određenih opštih vitalnih standarda od strane eksperata za određene oblasti.
\end{abstract}

\section{Ključne reči:}

zavarivanje, terminologija, standard, funkcija.

\section{Abstract:}

In engineering, as in other fields of science, it is very important to precisely and clearly define certain terms. In welding, it is also necessary to have generally accepted terminology understandable to everyone. Inconsistent terminology can create huge problems in everyday work, communication, and it surely leads to mistakes, because people tend to understand the same terms differently. Unfortunately, as a result of this, even a human life can be lost. In the past, this area was arranged by Serbian standards. However, the adoption of new international standards without translation into the Serbian language and termination of validity of the old ones creates new problems. In addition, the development of electronics has triggered revolutionary development of devices with many new functions. Therefore, the questions imposes as to whether the names of those functions should be translated or not, as there isn't often an appropriate term, regardless of the richness of the Serbian language.

The aim of this paper is to present the current terminology and the appropriate standards in welding using a variety of examples, as well as to point out to the necessity of introducing professionalism at work, and in the process of translating certain general and important standards by experts in the related fields.

\section{Key words:}

welding, terminology, standard, function.

\section{Zahvalnost}

Rad je proistekao iz istraživanja na projektu Ministarstva prosvete, nauke i tehnološkog razvoja, TR 35024 “Istraživanje mogućnosti unapređenja tehnologije zavarivanja mikrolegiranih čelika”.

\section{UVOD}

Zavarivanje je način spajanja dva materijala u neraskidivu vezu pomoću toplotne i/ili mehaničke energije, sa ili bez dodatnog materijala. To je jedan od najvažnijih tehnoloških procesa u savremenoj industriji, posebno u mašinogradnji, građevinarstvu, brodogradnji i procesnoj industriji (Sedmak et al.,2000). Iako se na primere zavarenih spojeva može naići i u dalekoj prošlosti, konvencionalni postupci zavarivanja pripadaju novijim tehnologijama. Primera radi, danas najzastupljeniji postupci zavarivanja u zaštiti inertnih i aktivnih gasova (MIG/MAG postupci, TIG postupak) otkriveni su tek četrdesetih i pedesetih godina prošlog veka. I u našoj zemlji (odnosno nekadašnjoj Jugoslaviji) zavarivanje počinje značajnije da bude prisutno tek pedesetih godina prošlog veka, kada zavareni spojevi potpuno izbacuju zakivke sa velikih konstrukcija. Zahvaljujući brojnim prednostima u odnosu na druge tehnologije, pre svega u povećanju čvrstoće i smanjenju mase konstrukcije, zavarivanje postaje dominantna tehnologija spajanja. Paralelno sa velikim industrijskim razvojem bivše Jugoslavije, razvijali su se i postupci zavarivanja, pa su praćena najnovija svetska dostignuća. Prvi standard iz ove oblasti objavljen je već 1961. godine pod nazivom „Tehnika varenja metala" kojim se definišu nazivi i pojmovi iz zavarivanja. Već 1972 . godine usvaja se izmena ovog standarda pod nazivom „Tehnika zavarivanja metala. Definicija pojmova i nazivi“. Ovaj standard je bio u upotrebi sve do 2012. godine kada je povučen zbog usklađivanja sa evropskim normama. Svima koji su učili zavarivanje, prvo kao studenti, a i kasnije kroz naučno-istraživački rad, ovaj standard je bio osnova i vodič za biranu stručnu terminologiju. Ovde treba obratiti pažnju na činjenicu da je već 1972. godine uveden pojam zavarivanje umesto dotadašnjeg varenje. Bez ulaženja u lingvističku analizu ovih pojmova, činjenica je da se i posle četrdeset godina, kako u sredstvima javnog informisanja, tako i u stručnim krugovima, može naići na pojam varenje, varilac i sl. Iako nije direktno u vezi sa zavarivanjem, sličan „problem“ postoji i oko pojma železa i gvožđa. Naime, gvožđe je, kao što se iz hemije uči, hemijski 
element, u periodnom sistemu označen simbolom Fe. Međutim, u oblasti materijala i metalurgije u Srbiji, više od 60 godina, naziv za čist hemijski element Fe je železo, dok su gvožđa legure železa i minimalno $2 \%$ ugljenika. Sa ovom terminologijom studenti se prvi put susreću na fakultetu ili u pojedinim srednjim stručnim školama, mada postoji snažan pritisak srednjoškolskih profesora hemije da se pojam železa izbaci iz upotrebe.

\section{POSTOJEĆE STANJE STANDARDA U OBLASTI ZAVARIVANJA U SRBIJI}

Prema definiciji, standard je dokument, utvrđen konsenzusom i odobren od priznatog tela, kojim se utvrđuju, za opštu i višekratnu upotrebu, pravila, smernice ili karakteristike za aktivnosti ili njihove rezultate, radi postizanja optimalnog nivoa uređenosti u datom kontekstu. U Jugoslaviji, zavarivanje je, kao i u drugim oblastima, bilo definisano standardima, prema tada važećem JUS-u. Podrazumevalo se da je standard na srpskom jeziku, što nije ostavljalo prostora za nedoumice. Naravno, terminologija koja se koristila u standardima i srodnim dokumentima razvijala se i menjala kroz decenije, te su nazivi područja, grupa i podgrupa vremenom menjani. Početkom ovog veka, počinje usklađivanje standarda sa važećim standardima Evropske unije, pa su naši standardi u početku prilagođavani, a zatim se prešlo na potpuno preuzimanje važećeg EN standarda. Pri preuzimanju su korišćene uglavnom tri metode usvajanja standarda: metoda proglašavanja, metoda preštampavanja i metoda prevođenja na srpski jezik. Metoda prevođenja na srpski jezik je korišćena najmanje jer je njena primena zavisila isključivo od spremnosti zainteresovanih strana da u prevođenje standarda dobrovoljno investiraju potrebna sredstva i/ili rad svojih stručnjaka. Samo u 2013. godini Institut za standardizaciju Srbije je objavio 3325 srpskih standarda i srodnih dokumenata, od kojih je 176 objavljeno na srpskom, a 3149 na engleskom jeziku, što predstavlja čitavih 95\% ukupnog broja (Aleksić et al., 2014). Dakle, evropski standard prihvata se bez ikakvih modifikacija kao srpski standard na engleskom jeziku.Verzija evropskog standarda postoji u tri zvanične verzije; na engleskom, francuskom i nemačkom jeziku. Verzija na bilo kom drugom jeziku prevedena sa originala može se usvojiti kao zvanična uz saglasnost nacionalnog tela. Ali na koji način to sprovesti u delo? U okviru Instituta za standardizaciju postoji komisija nadležna za standarde iz oblasti zavarivanja i srodnih postupaka, i formalno, usvajanje na srpskom jeziku nije problem. Međutim, manje je poznato da postoji nedovoljno učešće stručnjaka koji imaju vremena i volje da dobrovoljnim radom u komisijama za standarde doprinesu donošenju srpskih standarda i srodnih dokumenata, kao i njihovoj harmonizaciji sa međunarodnim i evropskim. Paralelno sa tim postoji i nezainteresovanost stručne javnosti za učešće u javnoj raspravi i dostavljanje primedbi i predloga u vezi sa nacrtima srpskih standarda i srodnih dokumenata koji se stavljaju na javnu raspravu. I na kraju, ključni problem je nezainteresovanost države da prizna i uvede profesionalizam u radu i prevođenju određenih opštih vitalnih standarda od strane eksperata za određene oblasti koji potiču iz privrede, a prednjače znanjem u radu u ovoj oblasti.

Primera radi, standard SRPS EN ISO 4063:2007 „Zavarivanje i srodni postupci-Lista postupaka i njihovo označavanje“ definiše nazive postupaka i nomenklaturu njihovog označavanja (Zbirka standarda, 2012). Ovaj standard je bio na srpskom jeziku, ali je 2013. godine zamenjen standardom SRPS EN ISO 4063:2013 istog naziva, dva puta obimnijeg (33 strane u odnosu na prethodnih 17 strana), ali na engleskom jeziku. Dakle, više ni najosnovniji standard koji definiše kako se koji postupak naziva više nije na maternjem jeziku. Koliko je važno jasno definisati određene pojmove, kao i da su to prepoznale i druge zemlje, pokazuje i standard SRPS EN 1792:2012 „Zavarivanje-Višejezička lista termina za zavarivanje i srodne postupke" koji na 92 strane daje liste opštih termina iz zavarivanja koji se upotrebljavaju, i to paralelno na engleskom, francuskom i nemačkom jeziku. Naravno, i ovaj standard je usvojen bez prevoda, odnosno ostajemo bez ovih pojmova na srpskom jeziku. Bilo je pokušaja u domaćoj stručnoj javnosti da se ovaj standard prevede, pa je u časopisu „Zavarivanje i zavarene konstrukcije“"u nekoliko brojeva izlazio prevod delova standarda, ali nažalost, to nikada nije usvojeno (Rečnik, 2011).

\section{PREVOD ILI NE?}

Koliko god da je važno da bar najvažniji standardi iz određene oblasti budu na srpskom jeziku, jasno je da se ne može sve prevesti, pa se čak negde postavlja i pitanje da li je prevod neophodan.

U prethodnih 60 godina u zavarivanju je uspostavljena važeća terminologija i napravljen je uravnotežen pristup usvajanju stranih termina, ali i pronalaženju adekvatnih srpskih izraza. Tako na primer, za jednu od zona zavarenog spoja, koja na engleskom ima skraćenicu HAZ (Heat Affected Zone), usvojena je takođe skraćenica ali na srpskom jeziku ZUT (Zona Uticaja Toplote) i to je zvaničan naziv ove zone. S druge strane, opšte prihvaćene skraćenice postupaka zavarivanja skoro u svim zemljama Evrope, poput MIG postupka (Metal Inert Gas), MAG postupka (Metal Active Gas), TIG postupak (Tungsten Inert Gas), zadržane su i usvojene i kod nas bez prevođenja.

Kao dobar primer usvajanja termina treba navesti primer jednog novog postupka zavarivanja. Friction stir welding je relativno mlad postupak zavarivanja u čvrstom stanju nastao na Institutu za zavarivanje u Londonu krajem 1991. godine, a prvi međunarodni standardi usvojeni su 2011. godine. Od samog početka postoji veliko interesovanje za ovaj postupak u Srbiji, pa su usledili prvi naučno stručni radovi, projekti i istraživanja, odbranjene su prve doktorske disertacije. Pri tome su autori, za početak, imali problem kako da nazovu navedeni postupak o kom se radi. Pojmove vezane za ovaj postupak tumačili su na svoj način, koristili engleske termine, stvarali svoje na maternjem jeziku, a u zavisnosti od potreba rada ili svojih govornih sklonosti (Mijailović et al., 2011). U tom periodu postoji nekoliko naziva istog postupka, korišćenih čak i u doktoratima, od čisto engleskog naziva Friction stir welding, preko Zavarivanja trenjem sa trnom, Zavarivanja trenjem pomoću alata, pa do najnovijih nastojanja da zvaničan naziv bude Zavarivanje trenjem sa mešanjem, i zvanične skraćenice ZTM. Postoji raspoloženje stručne javnosti za prihvatanjem ovog termina, ali je neophodno da uđe i u standard.

Svedoci smo da nove tehnologije dovode do uvođenja novih izraza i termina. Razvoj elektronike, kao i u drugim oblastima života, omogućio je revolucionaran razvoj uređaja za zavarivanje i otvorio čitav spektar novih mogućnosti. Moderna elektronika i kompjuterska tehnika imaju značajan uticaj na razvoj opreme i novih funkcija. Svakodnevno, na tržištu se pojavljuju uređaji sa unapređenim performansama koje olakšavaju samo zavarivanje i doprinose kvalitetnijem zavarenom spoju. Pošto se podrazumeva da inženjeri, koji se i prvi susreću sa tim najnovijim uređajima i funkcijama, vladaju engleskim jezikom, a često i zbog nepostojanja adekvatnog termina, bez obzira na bogatstvo srpskog jezika, nazivi tih funkcija se usvajaju u originalu. Tako imamo pojmove: Creep start, Hot start, Lift arc, Wise root, Key hole, twin-arc i slično (Karastojković et al., 2010). Uz sve napore, adekvatni termini na srpskom jeziku zvuče prilično nezgrapno, pa je po nepisanom dogovoru odlučeno da se i ne prevode. 
Međutim, dolazi se u situaciju kada te termine treba objasniti tehničarima i zavarivačima koji, čast izuzecima, često ne vladaju stranim jezicima. Engleska terminologija ograničena je na mali broj ljudi i tada nastaje problem. Trenutno se problem rešava tako što se zavarivačima objašnjava šta ta funkcija omogućava i princip po kom radi, a ne prevod samog naziva, pa ga i oni sami usvajaju na engleskom jeziku bez razumevanja značenja. To definitivno nije rešenje, jer se dešavaju greške pošto ljudi pod istim imenom podrazumevaju različite pojmove. Dolazi i do problema na stručnim ispitima (za specijaliste, inženjere zavarivanja, tehnologe zavarivanja i sl.), na kome polaznici često ne razumeju pitanje, što zbog neadekvatnog prevoda samog pitanja koje je prosleđeno na stranom jeziku, što zbog neznanja stručne terminologije.

Iako smo se do sada bavili samo problematikom prevođenja sa stranog jezika, treba naglasiti da neusklađeni termini postoje i za čisto srpske reči. Neki će pod zavarom podrazumevati zavareni spoj, dok je to u stvari deo metala šava nastao u jednom prolazu; dešava se da, ne samo studenti, već i inženjeri, upotrebljavaju termine dodati materijal i žičana elektroda umesto dodatnog materijala i elektrodne žice, što je nedopustivo. Neki i dalje vare, umesto da zavaruju, heftaju umesto da pripajaju, odomaćio se "majstorski" naziv šoba umesto mlaznica, brener umesto gorionik i sl. Ako bi se kod dve firme koje prodaju materijale za zavarivanje uporedile liste proizvoda, na prvi pogled bi se zaključilo da prodaju potpuno različite proizvode, jer se potpuno drugačije zovu, iako su u $90 \%$ slučajeva identični. Čini se da su se tu umešale i struke koje ne poznaju čak ni sam proces. Jedan od novijih delova opreme za TIG postupak zavarivanja je engleskog naziva gas lens. Bez objašnjavanja čemu to služi, trenutno su opcije naziva ovog dela: nosač volframove elektrode sa mrežicom, raspršivač sa sitom i gasna mrežica. Često je neophodno da deo pokažete na slici, da bi ste kupili šta želite.

\section{REZIME}

U svakoj struci veoma je važno precizno i jasno definisati određene pojmove. Tako je i u zavarivanju, kao grani tehnike, neophodno postojanje opšteprihvaćene terminologije razumlji- ve svima. Nedosledna terminologija pravi probleme u radu, komunikaciji i dovodi do grešaka, jer ljudi pod istim imenom podrazumevaju različite pojmove. Jedan od osnovnih uzroka problema je neprevođenje standarda na srpski jezik, već samo preuzimanje na engleskom jeziku. Čini se da je razlog nedovoljno učešće stručnjaka koji imaju vremena i volje da dobrovoljnim radom u komisijama za standarde doprinesu donošenju srpskih standarda i srodnih dokumenata, kao i njihovoj harmonizaciji sa međunarodnim i evropskim standardima. Dalje, problem je nezainteresovanost države da prizna i uvede profesionalizam $u$ radu i prevođenju određenih opštih vitalnih standarda od strane eksperata za određene oblasti, odnosno, država bi morala zahtevati, definisati ali i finansirati određeni broj prevedenih srpskih standarda iz svake oblasti. Konačno, pošteno je priznati i da bi veći broj objavljenih, pre svega, univerzitetskih udžbenika iz zavarivanja uveo više reda u ovu oblast.

\section{LITERATURA}

Aleksić, B., Bađura, V., Stefanović, A., Kurai, J., \& Jovanović. D. (2014). Current conditions of standards in welding in Serbia. Welding and welded structures, 59(4), 190-191.

Karastojković, Z., Kovačević, Z., \& Srećković. M. (2010). Kako na srpski prevoditi zavarivački termin "key hole". Welding and welded structures, 55(3), 37-38.

Mijailović, M., Milčić, D., Đurđanović, M., Grabulov, V., Živković, A., \& Perović. M. (2012). Osnovni pojmovi kod postupka zavarivanja trenjem sa mešanjem prema AWS D17.3/ D17.3M:2010 i ISO 25239-1:2011. Welding and welded structures, 57(2), 61-68.

Rečnik.(2011). Englesko-srpska lista termina za zavarivanje i srodne postupke: Izvod iz standarda SRPS EN 1792:2008. Welding and welded structures, 56(1), 37-38.

Sedmak, A., et al. (2000.). Mašinski materijali-drugi deo. Beograd: Mašinski fakultet

Zbirka srpskih standarda. (2012). Obezbeđenje kvaliteta u zavarivanju. Tehnologija zavarivanja. Beograd: Institut za standardizaciju Srbije, Društvo za unapređenje zavarivanja u Srbiji. 